\title{
Incentives to lose revisited: The NHL and its tournament incentives
}

Helena Fornwagner

Working Papers in Economics and Statistics 2017-07

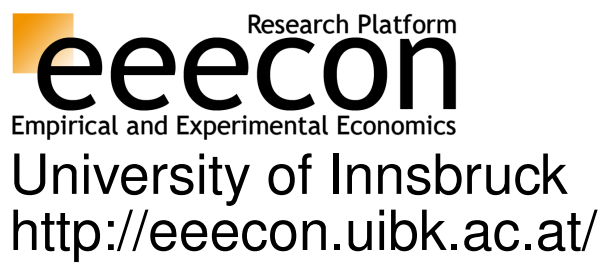




\section{University of Innsbruck \\ Working Papers in Economics and Statistics}

The series is jointly edited and published by

- Department of Banking and Finance

- Department of Economics

- Department of Public Finance

- Department of Statistics

Contact address of the editor:

Research platform "Empirical and Experimental Economics" University of Innsbruck

Universitaetsstrasse 15

A-6020 Innsbruck

Austria

Tel: $\quad+435125077171$

Fax: $\quad+435125072970$

E-mail: eeecon@uibk.ac.at

The most recent version of all working papers can be downloaded at http://eeecon.uibk.ac.at/wopec/

For a list of recent papers see the backpages of this paper. 


\title{
Incentives to lose revisited
}

\author{
The NHL and its tournament incentives
}

\author{
Helena Fornwagner*
}

April 24, 2017

\begin{abstract}
This paper analyzes data from a tournament, namely the National Hockey League regular scheduled season of games, which provides incentives to increase effort in order to reach the playoffs and incentives to decrease effort once a team has been eliminated from playoff considerations because of the entry draft. Our results show that teams indeed react to these dual incentives - they win more games when there is still a chance to reach the playoffs and lose more after being eliminated from playoff considerations. One can argue that losing more games after having no more chance to reach the playoffs could be the result of lower motivation or disappointment. This is the first study to show that this is not the only explanation for a higher amount of lost games. Instead, we find that there is a concrete strategy behind losing.
\end{abstract}

JEL-Classification: C93, D03, L83, M52

Keywords: tournaments, dual incentives, National Hockey League, losing strategy

\footnotetext{
*Department of Public Finance, University of Innsbruck. E-mail: helena.fornwagner@uibk. ac .at

${ }^{\dagger}$ This project originated through discussions with David Schindler and Florian Lindner. Further, I want to thank Loukas Balafoutas who always supported my research in every different state. I would also like to thank Janette Walde especially for helpful comments on econometric topics. Further, I would like to thank participants at the research seminar at the Institute of Industrial Economics in Stockholm, seminar participants at the University of Prague, and participants at the Euregio Workshop 2016 for their helpful comments and suggestions. I am also thankful to Saskia Paetzhold, Lukas Sattler, and Christian Hainisch, who helped with the data collection.
} 


\section{Introduction and Related Literature}

Does one of the oldest sport leagues in the world, the National Hockey League (NHL), provide incentives which contradict the spirit of what sports should in general be all about: two teams putting as much effort as possible into winning a game ${ }^{1}$ Although this statement is frequently discussed in the media and points toward a major problem in the world's premier professional ice hockey league, no study exists about the NHL providing incentives to decrease effort and teams reacting to this incentives in a strategic way. Generally, tournament theory suggests that higher effort is rewarded (Lazear and Rosen, 1981). This paper investigates, by analyzing NHL data from 26 NHL seasons, why teams could also face incentives to decrease effort within a tournament and shows that they decrease effort in line with these incentives. Moreover, it is the first to show that their decrease in effort is the result of a concrete strategy that cannot only be explained by lower motivation.

Even though the classical tournament theory by Lazear and Rosen (1981) was developed to determine optimal labor contracts for organizations, Frick (2003) showed that the special characteristics of team and individual sport tournaments make these tournaments a perfect environment to test tournament theory. This is the case because it is rather easy to observe the effects of tournament incentives on performance and infer provided effort from performance. Therefore, it is no surprise that researchers started to test the predictions of tournament theory with sport data in the early 1990s. ${ }^{2}$ These studies used for example data from golf (Ehrenberg and Bognanno, 1990a,b), bowling (Bognanno, 1990), and professional horse racing tournaments (Fernie and Metcalf, 1996, 1999; Lynch and Zax, 1998). Tournament theory has also been tested by experimentalists over the recent decades, who have analyzed various predictions with data from experiments. For an overview of tournament theory tested in the lab see the survey from Szymanski (2003) and Dechenaux et al. (2015) provide a comprehensive review of experimental research done in the lab and in the field.

1 See for example the following websites for these discussions: http://www.habseyesontheprize.com/nhlentry-draft-picks/2017/3/27/15068694/2017-nhl-entry-draft-lottery-positioning-standings-avalanchecoyotes-nolan-patrick-liljegren, http://edmontonjournal.com/sports/video-on-the-shameless-nhl-draftlottery-race-to-the-bottom, http://www.winnipegfreepress.com/sports/hockey/jets/race-to-the-bottompromises-prime-pick-in-talent-rich-draft-373025711.html

2 An additional argument for using sport data is that many organizational issues present in companies are also present in sport tournaments (e.g., leadership, management, biased decision making). 
Preston and Szymanski (2003) turned tournament theory on its head when they showed that, in certain contexts, not only the idea of "the higher rank the better" drives the behavior of agents when they are competing against each other. Instead, they identified an additional incentive present in specific famous sport tournaments that influences the effort provided by sport agents: Besides the already known incentives to provide higher effort to win a contest (Lazear and Rosen, 1981), in some tournaments, additional incentives lead sport agents to decrease effort to lose the contest rather than to win it. This creates so called "dual tournaments" within one league, where some agents increase effort to win the contest and other agents in the same league decrease effort to lose games. Examples for dual tournaments outside the sports world include the U.S. welfare system and international pollution standards (Taylor and Trogdon, 2002). The problem with these non-sport tournaments is the following: effort put forth by agents is hardly observable because it can not be perfectly inferred from observable performance. Therefore, Taylor and Trogdon (2002) point out how important it is to study the behavior of agents using sport data, where effort is observable, and one can monitor how agents react to different or changing incentives.

This paper contributes to the literature on dual tournaments. Taylor and Trogdon (2002) were the first to examine if the underlying tournament incentives provided by the National Basketball Association's (NBA) introduction and reconstruction of the lottery system to determine draft order had an influence on the provided effort of the playing teams. Their results showed that in the presence of losing incentives, teams were more likely to lose. Price et al. (2010) used a fixed effect rather then a random effect regression and a larger data set to replicate the findings. Their results also showed that agents lost more when losing incentives were present. In line with these findings, Balsdon et al. (2007) found evidence of more lost games in the National Collegiate Athletic Association (NCCA) whenever incentives to provide lower effort were put in place. On the contrary, Borland et al. (2009) found no lower provided effort in the Australian Football League when incentives to lose were present. They stated that this result could be explained by insufficient large benefits of being lower ranked in the league.

Since intentionally providing lower effort can be viewed as an undesirable behavior in sport tournaments, this paper also contributes to the literature on unethical behavior in sports in general. Sabotage on the part of athletes was for example reported by 
Duggan and Levitt (2002), Garicano and Palacios-Huerta (2005), Dietl et al. (2010), and Balafoutas et al. (2012) among others. Unethical behavior was also found on the part of sports officials for example by Sutter and Kocher (2004), Zitzewitz (2006), Parsons et al. (2007), and Price et al. (2007, 2009). Dietl et al. (2009) showed that making officials aware of present unethical behavior helped to reduce the opportunities for unethical behavior.

The rest of the paper is organized as follows: The next section describes why the NHL provides incentives to decrease effort and how these have changed over seasons. After discussing our dataset in Section 3, we show in Section 4 that teams decreased effort if incentives to lose were in place. Section 5 explains the strategy behind providing lower effort. Section 6 concludes the paper and discusses how the incentives to lose could be decreased.

\section{Incentives to win and lose}

As every other sport tournament, the NHL provides in the first place incentives to win a game. The more victories a team collected during a season, the more likely it is to secure a Stanley Cup playoff spot. The playoffs (PO) are the NHL finals where the top 16 teams of the league are competing for becoming the NHL league's champion. How a team qualified for the PO changed over the years. ${ }^{3}$ Playing at the PO is not only an honor, it also directly influences team's revenues (e.g., more sponsors, more sold tickets, fan articles ect.) and is therefore the most desirable outcome for a team within a season. Yet, the NHL provides incentives to lose in addition to the winning incentives leading to a dual tournament. Like in other North American sports leagues, this is caused by the Entry Draft (ED) system.

\subsection{General information on Entry Drafts}

In sports like hockey, basketball, baseball, and football, the ED is used as a process to allocate newly eligible players to teams. ${ }^{4}$ Using an ED is most common in American and Canadian sport leagues. An ED includes in general different turns, where in every turn one

3 See, e.g., https://en.wikipedia.org/wiki/Stanley_Cup_playoffs for an overview.

4 The other draft systems are the expansion draft and the dispersal draft. Under the first one newly founded teams select players from other teams in the league, while in the latter one the league's surviving teams select players from the roster of newly defunct teams. 
team selects one player from the pool of eligible players. When a team chooses a player, the team receives exclusive rights to sign that player to a contract. This means that no other team in the league may sign him. Which team has the right to pick first, second, and so on from the pool of newly eligible players is determined by the draft selection order (DSO). Generally, the worse teams in the league will pick earlier than higher ranked teams. This is caused by the intentions of the ED: Most important, it should promote competitive balance in the sense that best incoming talents in each season should be allocated to the worse teams to equalize participating teams in the long term. In other words, the ED gives poorly performing teams the opportunity to improve team strength by signing potential new superstars when picking earlier, and it ensures that no single team can sign contracts with all of the best young players. Further, the ED prevents expensive bidding wars for young talents.

However, it is questionable whether an ED really promotes competitive balance. Tingling et al. (2011) found evidence that the new eligible high quality NHL players were indeed signed by the worst teams. Moreover, Grier and Tollison (1994) presented some empirical evidence that EDs in professional football promote competitive balance and Maxcy (2002) argued that competitive balance also improved with the implementation of the ED in the Major League Baseball. In contrast, other authors like ,e.g., Rottenberg (1956) found no evidence of EDs balancing out team strengths. He showed in the context of the baseball players' labor market that the most productive players will eventually play for the teams that value them the highest, independent of the initial allocation of players. In addition, Quinn (2008) reported no relationship between competitive balance and EDs when looking at the major North American sports leagues for football and basketball. An explanation for the ineffectiveness of EDs was given by Szymanski (2007), Quinn (2008), as well as Rottenberg (1956). They argued that a restraint of player transfer is needed after the ED to assure that the high draft picks remain at the low-ranking teams. 


\subsection{The NHL Entry Draft}

For the NHL, its ED is an annually held meeting, generally within two to three months after the conclusion of the previous season. At this meeting, franchises take different turns (generally seven turns with one selection per team per turn) selecting the rights to available amateur players from junior, collegiate or European leagues, who meet draft eligibility requirements. Until now the determination of the DSO at the NHL ED changed five times (see Figure $\left.1^{5}\right) .^{6}$

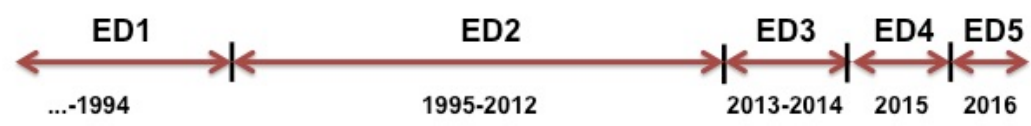

Figure 1: NHL ED changes

ED 1: From the beginning of the NHL up to 1994, the order for all turns of the ED was solely determined by the reverse standings at the end of each season. This means that the last placed team got the first pick in all turns, the second last placed the second, and so on.

ED2: Starting in 1995, the first ED Lottery (EDL) was put in place, where only teams which missed the PO were allowed to participate in a lottery whose prize was the first draft pick. The probabilities of winning the lottery were weighted towards teams at the bottom of the regular season standings to give the worst teams the highest probability of winning (see Figure 2). For example the last-placed team had a $25 \%$ probability of winning the lottery, while the second-last-place team had a $18.8 \%$ probability of winning. Any team ranked higher in the regular season's standings compared to the lottery winner moved down a spot. In addition, the lottery winner could move up a maximum of four places at the DSO. In other words, only the top five-placed teams (the last five teams in the league's standings) could potentially pick first in the draft, and no non-PO (nPO) team could move down the DSO more than one place. This led to different de facto

5 For the remaining paper please note the following: we call a season season $t$ if this season includes games played in autumn of year t-1 until spring of year t. For example season 1988 consists of games played from October 8, 1987 until May 26, 1988.

${ }^{6}$ For more information about the changes see https://www.nhl.com/news/2013-nhl-draft-lotteryand-nhl-draft-information/c-658503 or https://www.nhl.com/oilers/news/past-results-of-the-nhlsdraft-lottery/c-668037 or https://www.nhl.com/news/2015-nhl-draft-lottery-procedure/c-763807 or https://www.nhl.com/news/nhl-announces-changes-to-draft-lottery-format/c-728795 An detailed explanation on how the ED lottery works is provided here: https://www.nhl.com/video/the-nhl-draftlottery-explained/t-277350912/c-43681503 
probabilities of winning the first pick, which were higher for the five last placed teams and zero for all other teams (see again Figure 2 for more details). Importantly, the lottery influenced only the first pick of the ED and only the ED's first turn of selection. The DSO for all following picks and following turns was again strictly defined by overall league rank (from worst to best).

ED3: Beginning in 2013, the existing lottery of ED2 was slightly adjusted. The EDL still influenced only the first pick of the DSO for the first turn of selection and also the probabilities of winning remained the same, but the restriction in movement was eliminated. This led to a situation where now all nPO teams had a chance to win the first overall pick for the first turn of the ED, even thought the probabilities of winning were low for higher performing teams.

ED4: The NHL officials announced in August 2014 two major changes for the following EDs. First, for ED 2015, the probabilities of winning the lottery for worst teams decreased and increased for better teams. This resulted in more equal probabilities for winning the lottery, all other things equal to the previous ED.

ED5: The second change was the adaption which took place in 2016 when for this $\mathrm{ED}$, the EDL still determined the DSO for the first turn for all nPO teams, but the top three picks in the draft - not just the top pick like in all previous seasons - were determined by the EDL. The probability of winning the first pick remained the same like in ED4 and the probabilities of winning the second and third draws increased on a proportional basis depending on which team won the first pick.

\subsection{Are there incentives to lose?}

When a season nears completion, teams that are for sure eliminated from PO considerations have an incentive to reduce their effort - and lose as many games as possible - in order to obtain better draft picks. This is the case because generally worse teams are assured better draft picks by the ED regulations. But is it really worth to start a race to the bottom after elimination in order to assure a higher pick?

A higher draft pick - generally expected from the league to be a better player - should increase a team's winning percentage in the next season. Tingling et al. (2011) show that NHL players chosen in the first turn and in the first half of the second turn of the ED are indeed significantly more successful, so choosing earlier rather than later is important 
for the first two turns. A related study by Berri (2008) for a similar tournament system (NBA) points out that the first draft pick is the best choice. The first drafted player produces a significantly higher number of wins over the first five seasons, compared to the second and third pick (second and third picks are not different according to average wins). Thus, having the right to pick first or earlier can generally be seen as a positive value for a team. This value can be used by actually drafting the players or it could also be traded away for other options, which is a common strategy in the NHL. Given these facts, if a team has been eliminated from PO considerations, it is in their best interest to assure the first or an earlier draft pick by starting a race to the bottom.

\subsection{The Entry Drafts' different losing incentives}

The higher the certainty for a team when ending up last (towards the bottom of the league's standings) to get the first (an earlier) pick, the stronger were the incentives to actually end up last (at a lower position). We used a probability analysis to investigate how the incentives to end up last or at a lower rank differed between EDs. This method was also used by Price et al. (2010), based on the work of Penrice (1995) and Florke and Ecker (2003) for the NBA's EDs. Figure 2 describes the unconditional probabilities of every NHL team to get the first pick, depending on the format of the ED and the team's rank. ${ }^{7}$

Under ED1, a team which was certainly not playing at the PO had high incentives to reach the bottom place because it assured the right to pick first. However, all teams placed between the second and the 14th place had a zero probability for the first pick, meaning that incentives to lose in order to get the first pick ceased to exist as soon as it became impossible for a team to finish last. Of course, in addition, it was always better to be placed at a lower position because this assured an earlier pick in all turns since the DSO for all turns was only influenced by the reverse league standings at the end of the season.

When the EDL was put in place in 1995 (ED2), the last placed team faced for the first time an uncertainty for getting the first pick (48\% probability to win the lottery whose prize was the first pick). So the prize of finishing last decreased compared to ED1, but on the other hand a higher number of teams had a positive probability of getting

\footnotetext{
7 Please note that rank "1" means that a team ended up last at the league's standings.
} 


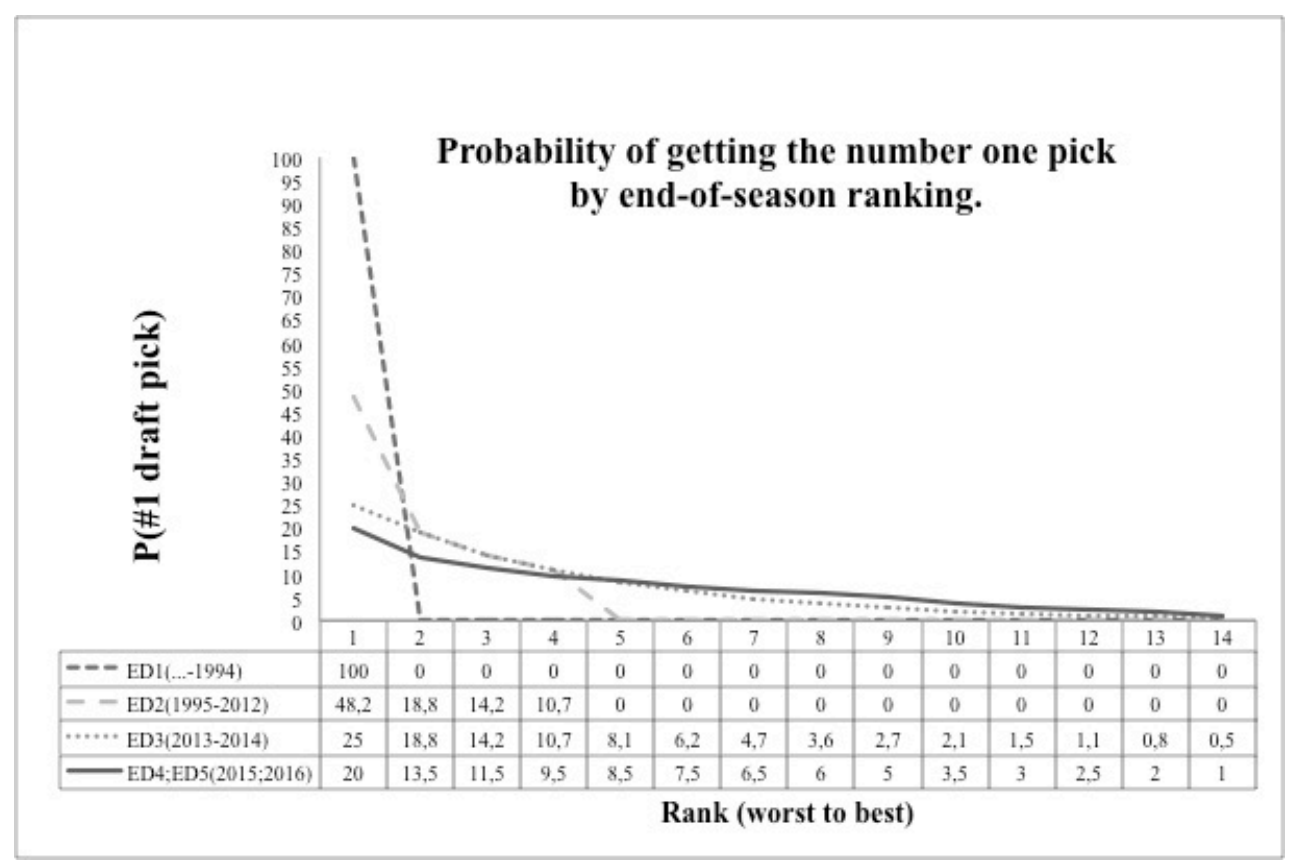

Figure 2: Probabilities of the different ED systems

that prize (those with a positive probability of finishing in the bottom four). This means that, overall, a comparison of the incentives to lose among the entire pool of nPO teams between ED1 and ED2 is not straightforward and it depends on the distance among nPO teams in the league table at each point in time.

When the restriction in movement was eliminated in 2013, the last placed team still had the highest probability of winning the lottery, but the probability was about half compared to ED2. So the uncertainty for the last placed team to win the lottery increased, but on the other hand all nPO teams now had a positive probability of securing the highest prize. In addition, like in ED1 and ED2, moving down the league's standings again assured a higher pick for subsequent turns.

Under ED4, the equalization of the winning probabilities further diminished the prize of finishing last (winning probability decreased from $25 \%$ to 20\%). The increase in the probability of getting the first pick by moving down a position was sometimes higher under ED3 (for instance when moving from rank 11 to 10 or from rank 7 to 6) and sometimes higher under ED4 (for instance when moving from rank 14 to 13 or 13 to 12).

The changes made for the EDL in 2016 did not affect the probability of getting the first pick, but this ED was the first stipulating that not only the first but also the second and the third pick were awarded by a lottery. This particularly increased the uncertainty for the last three placed teams to get a better pick. On the other hand, it increased the 
likelihood of lower placed teams to do so.

Overall, the above analysis reveals that, although the prize of finishing last consistently decreased over seasons (i.e. when moving from ED1 to ED2, ED3 and so on), the probabilities of securing the first prize generally increased for a large number of $\mathrm{nPO}$ teams. Hence, a conclusive comparison of the strengths of incentives to lose between different EDs is not possible; what we can say with certainty is that these incentives are present under every single ED.

\section{Data}

The largest part of the dataset has been retrieved from the NHL homepage (https://www.nhl.com). Additional data has been collected from the Hockey Summary Project. $^{8}$ Our data include information from seasons $1988-2016^{9}$, which leads to 46,452 observations in total at the team level. ${ }^{10}$ Seasons 1995, 2005, and 2013 were excluded due to lockouts (in 1995 and 2013 only half of the scheduled games were played and all games were canceled in season 2005). As a result, 26 seasons remained for our analysis where our data is restricted to games which were decided after the regular play time and did not end in a tie. ${ }^{11}$

The variables included in the dataset vary from variables capturing game level data (e.g., outcome of a game), team level data (e.g., what players played for one team), and player level data (e.g., time on ice for each player for a particular game). This multilevel data offered us a rich set of information for every game played and allowed us to construct each team's winning percentage at each point in the season. Further, we combined our data with information about the ED rules in place in each season and therefore were able to identify (using the daily point standings and the number of games remaining) the point in each season when teams for sure clinched a PO spot or were eliminated. ${ }^{12}$

8 For more information about the Hockey Summary Project please visit: http://hsp.flyershistory.com.

9 The data available on the NHL homage started in 1988. This is why we restrict our analysis to the time period 1988-2016.

${ }^{10}$ Having 46,452 observations at the team level implies having 23,226 observations at the game level and around 929,040 observations at the player level.

${ }^{11}$ We decided to make this step to make the observations over years as comparable as possible.

${ }^{12}$ A team was for sure eliminated from PO considerations if it had mathematically no more chance to reach a PO spot neither through the division nor through the conference. This means that we calculated for each team after each game their total amount of collected points until this game and then added the maximal amount of points that could be collected when winning all future games. Afterwards, we compared this number to the minimum amount of points needed to reach a PO spot. A team was mathematically 


\begin{tabular}{l|c|c|c} 
Game statistic & Observations & before elim & after elim \\
\hline Goals for i & 46,452 & 3.02 & 2.53 \\
Goals against i & 46,452 & 2.97 & 3.36 \\
Shoots for i & 46,452 & 29.20 & 27.40 \\
Shoots against i & 46,452 & 28.97 & 31.15 \\
Power play \% of i & 46,452 & 17.91 & 15.42 \\
Faceoff winning \% of i ${ }^{13}$ & 31,760 & 50.05 & 48.97 \\
Penalty killing \% of i & 46,452 & 81.92 & 79.98 \\
Attendance & 16,509 & $16,373.02$ & $16,168.76$
\end{tabular}

Table 1: Game statistics before and after elimination for nPO teams

\section{Are eliminated teams more likely to lose?}

We begin by showing average statistics for our dataset. In line with our hypothesis, elimination leads to a higher percentage of lost games. In particular, nPO teams lose $58.57 \%$ of their games before elimination and $64.15 \%$ afterwards (Chi square test, $\mathrm{p}=0.00$ ).

When looking at game statistics reported in Table 1 we see that teams decrease their performance after elimination: they shoot significantly fewer goals (t-test, $\mathrm{p}=0.00$ ), and have significantly fewer shots on the opponent's goal after elimination ( $t$-test, $\mathrm{p}=0.00$ ). On the other hand, the opponent shoots significantly more goals when team i has been eliminated ( $\mathrm{t}$-test, $\mathrm{p}=0.00$ ) and also significantly more shots on team i's goal ( $\mathrm{t}$-test, $\mathrm{p}=0.00$ ). In addition, team i had a significantly lower power play percentage (Wilcoxon rank sum test, $\mathrm{p}=0.00$ ) and a significantly lower faceoff winning percentage (t-test, $\mathrm{p}=0.00$ ) after elimination. ${ }^{14}$ Attendance is significantly lower after elimination (t-test, $\mathrm{p}=0.00$ ), which is not surprising and may well be caused by disappointment among the fans, but it could also means that fans anticipate strategic losing to some extent.

We use the model by Taylor and Trogdon (2002) to analyze if eliminated teams are more likely to lose games. The empirical baseline model is the following:

eliminated from the PO if it could not exceed the minimum amount of points needed for a PO spot any more.

${ }^{13}$ The faceoff winning percentage was recorded from 1999 on. Therefore the number of observations is lower.

14 The power play percentage is calculated by dividing power play goals by power play opportunities. The faceoff winning percentage measures the rate at which a team wins faceoff draws. It is calculated in the following way: Faceoff winning percentage $=$ faceoffs won $/$ (faceoffs won + faceoffs lost). The penalty killing percentage measures the rate in which a team prevents their opponents from scoring when the team is at a man disadvantage due to a penalty (the opposing team is on a power play). The penalty killing percentage is equal to the power play opportunities minus the power play goals against. Then this number is divided by the power play opportunities against. 


$$
W I N_{i j k}=f\left(H O M E_{i j k} ; W I N P C T_{i j k}, O W I N P C T_{i j k},\right.
$$

$$
\left.C L I N C H_{i j k}, O C L I N C H_{i j k}, E L I M_{i j k}, O E L I M_{i j k}\right)
$$

where

$$
\begin{aligned}
& \mathrm{WIN}=\quad \text { a dummy variable equal to unity if team } \mathrm{i} \text { won game } \mathrm{j} \text { in season } \mathrm{k} \text {; } \\
& \mathrm{HOME}=\quad \text { a dummy variable equal to unity if team i played game } \mathrm{j} \text { at its home } \\
& \text { court in season } \mathrm{k} ;{ }^{15} \\
& \text { WINPCT }=\text { the winning percentage (number of wins/games played) of team } \mathrm{i} \text { at the } \\
& \text { time of game } \mathrm{j} \text { in season } \mathrm{k} \text {, to control for team strength; } \\
& \text { OWINPCT }=\text { team i's opponent's winning percentage at the time of game } \mathrm{j} \text { in season } \\
& \mathrm{k} \\
& \mathrm{CLINCH}=\quad \text { a dummy variable equal to unity if team i had clinched a PO spot at the } \\
& \text { time of game } \mathrm{j} \text { in season } \mathrm{k} ;{ }^{16} \\
& \text { OCLINCH }=\text { a dummy variable equal to unity if team i's opponent had clinched a PO } \\
& \text { spot at the time of game } \mathrm{j} \text { in season } \mathrm{k} \text {; } \\
& \text { ELIM }=\quad \text { a dummy variable equal to unity if team i had been eliminated from PO } \\
& \text { consideration at the time of game } \mathrm{j} \text { in season } \mathrm{k} ;{ }^{17} \text { and } \\
& \text { OELM }=\quad \text { a dummy variable equal to unity if team i's opponent had been eliminated } \\
& \text { from PO consideration at the time of game } \mathrm{j} \text { in season } \mathrm{k} \text {. }
\end{aligned}
$$

Like Price et al. (2010), we estimate a logit model including all of the above variables as well as team, season, and opponent fixed effects. ${ }^{17}$ Moreover, we cluster all standard errors at the game level, because we have two observations for each game. Regression results (logit coefficients and the associated marginal effects) are provided by Table 2 (columns one and two).

${ }^{15}$ The NHL included in seasons 1993 and 1994 several neutral-site, regular-season games in non-NHL cities. Moreover, the NHL has a tradition of playing some games each year at neutral venue (e.g., Winter Classics, Heritage Classics, ect.). Since the total amount of all neutral-site games is small, we decided to code a game played at neutral venue as not playing at home for both teams and we did not include a variable NEUTRAL (a dummy variable equal to unity if team i played game $\mathrm{j}$ at a neutral site in season k). We also run all the following regressions with $N E U T R A L$ and all results remain qualitatively unchanged.

${ }^{16}$ When we defined the variable $C L I N C H$ we were aware of the fact that a team could clinch a PO spot either through the division or through the conference. The same is true for OCLINCH.

${ }^{17}$ In this setting, as mentioned by Price et al. (2010), it is important to control for unobservable team-level heterogeneity, because the decision to start a race to the bottom after being eliminated is made at least partly by the team's franchise. 


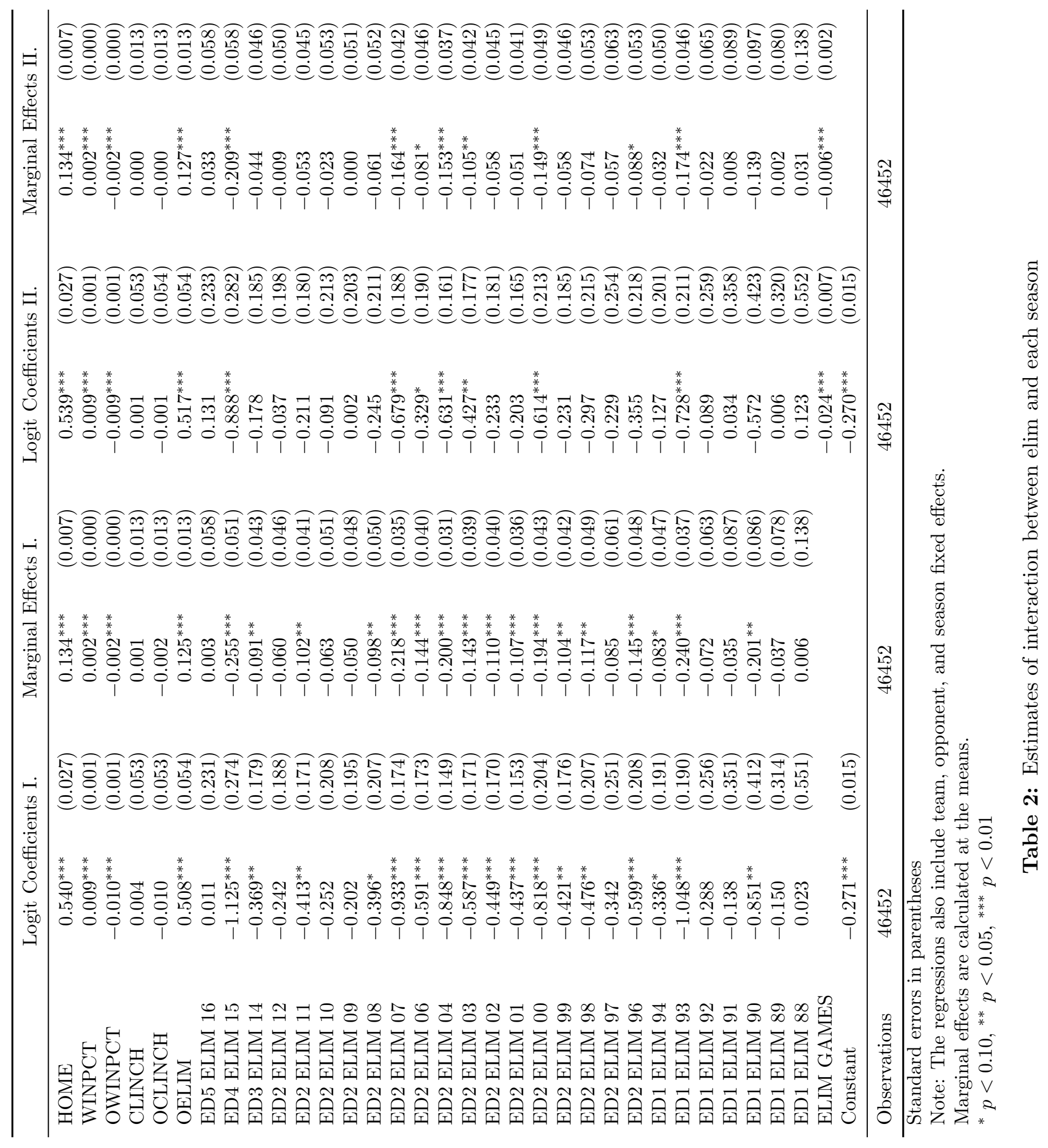


Our results reported in Table 2 confirm those of Taylor and Trogdon (2002) and Price et al. (2010). Playing at home increases team i's probability of winning by $13.4 \%$. The higher the winning percentage of team $i$, the more likely is team i to win the game. The opposite is true if i's opponent winning percentage is higher; the stronger the opponent in terms of winning percentage, the more likely is team $\mathrm{i}$ to lose. Whether team $\mathrm{i}$ or its opponent had clinched a PO spot is not influencing the winning probability. ${ }^{18}$

Our main variable of interest is the variable ELIM, which has been separated by season to capture seasonal changes of the incentives to lose games (e.g., the expected quality of new eligible players might be different over seasons). Which seasons are part of a certain ED scheme is indicated by the respective EDs. The size of the significant coefficients for ELIM varies between $9.1 \%$ and $25.5 \%$, which is mostly the same range as estimated by Price et al. (2010). Further, except for ED 1 ELIM 88 and ED 5 ELIM 16, which are insignificant, all coefficients for ELIM have a negative sign. This means that in 17 out of 26 seasons, being eliminated significantly decreases the probability of winning a game. Splitting up our results further, we find a significant negative effect of being eliminated on the winning probability in three out of seven seasons of ED1. Turning to ED2, the winning probability is significantly negatively influenced by having no more chance for a PO spot in $75 \%$ of the seasons.

The estimated insignificant coefficient for ED5 can be explained by the higher uncertainty for the last placed team of securing the first pick under this system, as we have already explained in Section 2. Another possible explanation could be that the incentives to get the first pick were not strong enough, because the quality of the eligible players was evaluated by the teams as being lower. When reviewing the media one has the impression that this could indeed be an explanation in this case (only three players were seen as outstanding $\left.{ }^{19}\right)$. Given that we have data only for one season of ED5, we can not yet identify the reasons behind this insignificant result. Concerning the size of the coefficients across different EDs, we note that the mean marginal effect of elimination was not significantly different in ED2 compared to ED1 ( $\mathrm{p}=0.46, \mathrm{~F}$-test), or ED3 ( $\mathrm{p}=0.47)$. It significantly increased from ED3 to ED4 ( $\mathrm{p}=0.02)$, revealing that the strongest effect appeared when

${ }^{18} \overline{\text { We share the view of Taylor and Trogdon }}$ (2002) why it is not surprising to get insignificant coefficients for $C L I N C H$ and $O C L I N C H$ : After being sure to play at the PO, some teams may have incentives to move up the league or conference rankings in order secure home advantage or more inferior opponents in the PO, while others may want to rest key players. Therefore, the expected signs of $C L I N C H$ and $O C L I N C H$ are a priori ambiguous and indeed the coefficients are insignificant.

${ }^{19}$ See, e.g., http://thehockeywriters.com/3-potential-2016-nhl-draft/ 
the probabilities of securing the first prize were relatively evenly spread between the nPO teams.

We also ran robustness checks to test if our regression results were influenced by league changes (structural- and other systematic-changes; see Appendix 7.1) or other influencing factors. Our results were not qualitatively different when we accounted for all changes regarding the league structure, rule changes, or different amounts of teams or games played. In addition, we ran our regressions also with the full data set (including games ending in a tie, games played until overtime, or games decided after a shootout). We also tested a regression with having won, lost, and tied as a categorical dependent variable. Further, we analyzed a probit regression. All of the above robustness checks did not produce qualitatively different results. Finally, we applied the baseline regression model to a number of different variables - other then winning - capturing team effort, namely the game statistics from Table 1. We found that all of these variables were also influenced by $E L I M$ as well as by our control variables in the expected direction. These regressions are provided in the Appendix (see Table 13).

The next question that directly arose after the initial analysis is: "Does it matter how long a team has been eliminated?" To test this we added to the baseline regression the variable ELIM GAMES, defined as the number of games since elimination at each point during the season. The earlier a team was eliminated, the earlier it could start a race to the bottom. This made longer eliminated teams more likely to decrease their effort in order to end up closer to the league's bottom. Our estimates are reported in Table 2 and show that the longer a team was eliminated, the significantly less likely it was to win the game. Each game played after elimination decreased the winning probability by $0.6 \%$ (the mean amount of games being eliminated is 9.17 and varied between 1 and 38 with a standard deviation of 6.90).

When looking at the seasonal effects of elimination one can see that in seven seasons there was also a significant direct effect of being eliminated in addition to the number of eliminated games. This effect is significant for $\operatorname{ED1}(\mathrm{p}=0.07, \mathrm{~F}$-test), ED2 ( $\mathrm{p}=0.01)$, and $\operatorname{ED} 4(\mathrm{p}=0.01)$. This is not the case for $\operatorname{ED} 3(\mathrm{p}=0.28)$ and $\operatorname{ED} 5(\mathrm{p}=0.69)$. Hence, controlling for the number of games after elimination still largely confirms our findings: being eliminated had a significantly negative effect on team i's winning probability for most seasons and this effect increased the longer team i has been eliminated. 


\section{$5 \quad$ Is there a strategy behind losing more games after elimination?}

Until now, our results suggest that teams act in line with the incentives provided to them - they lose more when incentives to lose are present. But how do we know that a significantly higher number of lost games after elimination is the result of a strategy? Only looking at game statistics does not rule out that a higher percentage of lost games is the result of lower motivation or disappointment.

\section{The strategy behind more lost games}

As mentioned in the Guardian (McIndoe, 2016), the order to decrease effort after elimination "comes from above - from the front office that assembles the roster, and who have the ability to ensure that the players who do take the ice have as little chance as possible" to win a game. Therefore, a testable hypothesis is that the team manager uses a lower quality team to reduce the winning percentage after elimination.

\begin{tabular}{lccccc}
\hline & I. TOI - all ED & II. TOI- ED2 & II. TOI- ED3 & II. TOI- ED4 & II. TOI- ED5 \\
\hline QUALITY & $121.389^{* * *}$ & $129.615^{* * *}$ & 22.627 & $58.396^{* * *}$ & $206.511^{* * *}$ \\
& $(4.012)$ & $(4.624)$ & $(14.442)$ & $(12.707)$ & $(13.680)$ \\
QUALITY x ELIM & $-141.494^{* * *}$ & $-145.822^{* * *}$ & $-98.391^{* * *}$ & $-120.940^{* * *}$ & $-120.770^{* * *}$ \\
& $(8.221)$ & $(9.437)$ & $(31.631)$ & $(22.649)$ & $(34.869)$ \\
Constant & $999.095^{* * *}$ & $996.822^{* * *}$ & $1005.776^{* * *}$ & $1004.021^{* * *}$ & $1013.745^{* * *}$ \\
\multicolumn{7}{c}{$(0.705)$} & $(0.805)$ & $(2.640)$ & $(2.437)$ & 16802 \\
\hline Observations & 244573 & 194925 & 17965 & 14881 & \\
\hline Standard errors in parentheses & & \\
Note: The regressions also include team, opponent, and season fixed effects. & \\
$* p<0.10,{ }^{* *} p<0.05,{ }^{* * *} p<0.01$ &
\end{tabular}

Table 3: Influence of player quality on player's time on ice 
To investigate if this is indeed the case, we tested at the individual level (244.573 observations $^{20}$ ) if high quality players played less after elimination. A player's quality was measured as the mean plus minus score a player had for all games before elimination $(\min =-2, \max =1.10$, std. $\operatorname{dev} .=0.17) .{ }^{21}$ How long a player plays in one particular game is measured in seconds and captured by the variable TOI (time on ice). We ran a regression with $T O I$ as dependent variable and measured how a player's quality influenced his $T O I$. The regression results are reported in Table3 and show that generally the higher the quality of a player, the significantly higher is the player's time on ice. Nevertheless, better players played significantly less after the elimination of their team, as captured by the negative interaction term $Q U A L I T Y \times E L I M$. These results confirm that team managers used a lower quality team after elimination. We think this identifies one strategy how team managers make their teams more likely to lose games after elimination. When we split up our results for the different ED systems (see again Table 3) we see that our results are robust for the individual EDs. Only for ED3 we have an insignificant coefficient for $Q U A L I T Y$, but the TOI is still significantly decreasing after elimination for higher quality players.

In addition, we looked at the total amount of shifts (shifts are known as substitutions in other sports like soccer) per team in each game. As the manager of a team decides who is shifted and how often in search of the optimal line up at each time during the game, we think that the total amount of team shifts is also a good proxy for how much effort the team manager is putting into his team winning a game. Indeed, if one regresses the winning probability on the number of shifts per game and a set of control variables, the results show a highly significant positive effects of shifts on the dependent variable (see Table 4 for the logit regression results with marginal effects calculated at the means).

We have information starting in season 1999 about how often a team manager shifted his players during a game $(\mathrm{N}=33,475)$. The mean amount of shifts for a nPO team

${ }^{20}$ We only included in our analysis players who did not quit during a season and who played for the whole season for the same team. Besides, we excluded goalies from these regressions because they are generally not shifted during a game (including these observations slightly shifts the coefficients of $Q U A L I T Y$ upward and of $Q U A L I T Y \times E L I M$ downwards but the results remain robust). The plus minus statistics are available since season 1999.

${ }^{21}$ The plus minus score is used to measure the player's impact on a game. A player is awarded a "plus" each time he is on the ice when his team scores an even-strength or shorthanded goal. He receives a "minus" if he is on the ice for an even-strength or shorthanded goal scored by the opponent. The difference between these numbers is considered the player's "plus-minus" statistic. See http://www.nhl.com/ice/page.htm?id=26374 


\begin{tabular}{lcccc}
\hline \multicolumn{4}{c}{ Logit Coefficients I. } & \multicolumn{2}{c}{ Marginal Effects I. } \\
\hline HOME & $0.601^{* * *}$ & $(0.032)$ & $0.147^{* * *}$ & $(0.008)$ \\
WINPCT & $0.010^{* * *}$ & $(0.001)$ & $0.002^{* * *}$ & $(0.000)$ \\
OWINPCT & $-0.009^{* * *}$ & $(0.001)$ & $-0.002^{* * *}$ & $(0.000)$ \\
CLINCH & -0.047 & $(0.071)$ & -0.012 & $(0.018)$ \\
OCLINCH & 0.082 & $(0.070)$ & 0.020 & $(0.017)$ \\
OELIM & $0.585^{* * *}$ & $(0.063)$ & $0.137^{* * *}$ & $(0.014)$ \\
ED5 ELIM 16 & -0.261 & $(0.186)$ & -0.065 & $(0.047)$ \\
ED4 ELIM 15 & $-0.315^{* *}$ & $(0.149)$ & $-0.078^{* *}$ & $(0.037)$ \\
ED3 ELIM 14 & -0.262 & $(0.174)$ & -0.065 & $(0.044)$ \\
ED2 ELIM 12 & -0.073 & $(0.187)$ & -0.018 & $(0.046)$ \\
ED2 ELIM 11 & $-0.457^{* * *}$ & $(0.167)$ & $-0.114^{* * *}$ & $(0.041)$ \\
ED2 ELIM 10 & 0.006 & $(0.195)$ & 0.002 & $(0.048)$ \\
ED2 ELIM 09 & -0.141 & $(0.191)$ & -0.035 & $(0.048)$ \\
ED2 ELIM 08 & -0.340 & $(0.211)$ & -0.085 & $(0.053)$ \\
ED2 ELIM 07 & $-0.852^{* * *}$ & $(0.166)$ & $-0.208^{* * *}$ & $(0.038)$ \\
ED2 ELIM 06 & $-0.527^{* * *}$ & $(0.169)$ & $-0.131^{* * *}$ & $(0.041)$ \\
ED2 ELIM 04 & $-0.696^{* * *}$ & $(0.155)$ & $-0.172^{* * *}$ & $(0.037)$ \\
ED2 ELIM 03 & $-0.405^{* *}$ & $(0.163)$ & $-0.101^{* *}$ & $(0.041)$ \\
ED2 ELIM 02 & $-0.434^{* * *}$ & $(0.167)$ & $-0.108^{* * *}$ & $(0.041)$ \\
ED2 ELIM 01 & $-0.546^{* * *}$ & $(0.161)$ & $-0.136^{* * *}$ & $(0.039)$ \\
ED2 ELIM 00 & $-0.857^{* * *}$ & $(0.207)$ & $-0.209^{* * *}$ & $(0.047)$ \\
ED2 ELIM 99 & -0.256 & $(0.187)$ & -0.064 & $(0.047)$ \\
SHIFTS & $0.018^{* * *}$ & $(0.000)$ & $0.005^{* * *}$ & $(0.000)$ \\
Constant & $-6.767^{* * *}$ & $(0.167)$ & & \\
\hline Observations & 33475 & & 33475 & \\
\hline Stan & & &
\end{tabular}

Standard errors in parentheses

Note: The regressions also include team, opponent, and season fixed effects.

SHIFTS is the total amount of shifts team i had in game $\mathrm{j}$ in season $\mathrm{k}$

${ }^{*} p<0.10,{ }^{* *} p<0.05,{ }^{* * *} p<0.01$

Table 4: Influence of shifts on the winning probability 
per game was 378.53. On average, nPO teams shifted significantly more before than after elimination ( 383.56 vs. $379.34, \mathrm{p}=0.00$, t-test), which further supports our second testable hypothesis that the effort put forth by the team manager decreased after elimination. Moreover, we run a OLS regression with shifts as the dependent variable. Over all EDs, the number of shifts was significantly lower after elimination ( $\mathrm{p}=0.00, \mathrm{~F}$-test) as reported in Table 5, confirming the statistical tests. Turning to other variables, teams shifted less when playing at home, the amount of shifts was lower for high quality teams and higher if a team played against a successful opponent, and playing against an eliminated team decreased the amount of shifts

\begin{tabular}{|c|c|c|}
\hline & \multicolumn{2}{|c|}{ SHIFTS } \\
\hline HOME & $-7.033^{* * *}$ & $(0.227)$ \\
\hline WINPCT & $-0.111^{* * *}$ & $(0.010)$ \\
\hline OWINPCT & $0.049^{* * *}$ & $(0.010)$ \\
\hline CLINCH & -0.589 & $(0.779)$ \\
\hline OCLINCH & 0.741 & $(0.716)$ \\
\hline OELIM & $-3.056^{* * *}$ & $(0.613)$ \\
\hline ED5 ELIM 16 & -2.988 & $(2.183)$ \\
\hline ED4 ELIM 15 & $-5.318^{* *}$ & $(2.078)$ \\
\hline ED3 ELIM 14 & $5.051^{* *}$ & $(2.276)$ \\
\hline ED2 ELIM 12 & $-6.835^{* * *}$ & $(2.613)$ \\
\hline ED2 ELIM 11 & $-4.062^{*}$ & $(2.206)$ \\
\hline ED2 ELIM 10 & -1.136 & $(2.260)$ \\
\hline ED2 ELIM 09 & -2.014 & $(2.509)$ \\
\hline ED2 ELIM 08 & $-5.237^{*}$ & $(2.681)$ \\
\hline ED2 ELIM 07 & 4.172 & $(2.863)$ \\
\hline ED2 ELIM 06 & 0.570 & $(3.522)$ \\
\hline ED2 ELIM 04 & -2.835 & $(2.371)$ \\
\hline ED2 ELIM 03 & $-4.634^{* *}$ & $(2.269)$ \\
\hline ED2 ELIM 02 & $-6.646^{* * *}$ & (1.773) \\
\hline ED2 ELIM 01 & -2.874 & $(2.327)$ \\
\hline ED2 ELIM 00 & 0.848 & $(2.624)$ \\
\hline ED2 ELIM 99 & $-11.489^{* * *}$ & $(2.358)$ \\
\hline Constant & $352.661^{* * *}$ & (1.687) \\
\hline Observations & 33475 & \\
\hline $\begin{array}{l}\text { Standard errors i } \\
\text { Note: The OLS } \\
\text { team, opponent, } \\
\text { fects. SHIFTS } \\
\text { shifts team i had } \\
{ }^{*} p<0.10,{ }^{* *} p<<\end{array}$ & $\begin{array}{l}\text { ntheses } \\
\text { on also inclu } \\
\text { season fixed } \\
\text { total amount } \\
\text { ne j in seasor } \\
{ }^{* * *} p<0.01\end{array}$ & \\
\hline
\end{tabular}

Table 5: Factors influencing the total amount of shifts 


\section{Conclusion}

In this paper we have analyzed how dual incentive structures in sport tournaments can make losing an attractive strategy. While previous studies using basketball data had found that dual incentives lead to more lost games, (Taylor and Trogdon, 2002; Price et al., 2010), no study has been able to show whether there is a strategy behind losing. Our paper is the first one to present field evidence that teams have a concrete losing strategy, beyond the possible effects of lower motivation or disappointment. We have exploited a natural experiment in hockey which included a dual incentive structure: incentives to win games to play a the $\mathrm{PO}$, and incentives to lose games after being eliminated from $\mathrm{PO}$ considerations.

Based on 23,226 games from the NHL hockey league from season 1988 to 2016 we have found that teams indeed lose more games after being eliminated. As an important complementary result we also showed that it is not only important to be eliminated, but the longer a team was eliminated, the significantly less likely it became to win a game. Importantly, having data on the individual player level made it possible to show that there is a strategy behind losing more. This is reflected in manager decisions that - on average - put a lower quality team on ice and shift less after elimination. We believe that our results should be taken into account when tournaments schemes such as the Entry Draft are designed, especially in an environment like sports, where it should be only about winning.

The limitations of our dataset do not allow us to study certain aspects that may be relevant for our research question, for example whether key players were more likely to be injured after elimination. In addition, we do not know if the lower quality players were younger players who were gaining game experience after elimination, in an effort to prepare them for the following season. Moreover, a very interesting question is if betting markets also anticipate more lost games after elimination (Price et al., 2010). This would provide insights into what further stakeholders like bettors believe about eliminated teams' performances. 
Is there a possibility to stop teams from decreasing effort after elimination? When reviewing articles, blog entries, and comments on various sites on the Internet, one comes across a number of alternatives already discussed by the public and experts. The most prominent solution was brought up by Gold (2010, 2011), whose idea was to incetivize winning games after elimination. - the team that wins the most games after being eliminated gets the first pick. Another way of giving nPO teams still an incentive to win games would be to put into place a single elimination tournament for nPO teams. A possibility how such a solution could look like is provided by Ralph (2016). ${ }^{22}$ An additional alternative mentioned by Ralph (2016) would be to invent a weighted EDL in which teams that narrowly missed the PO have the highest probability to win the first pick. This would rule out the problem of teams being stuck in the middle of the standings without any prospect of improving their situation for the upcoming season.

These alternatives suggest that there are ways of designing the DSO to decrease the incentives for teams to lose after elimination. However, it is questionable whether these alternatives would still promote the most important goal of the Entry Draft - "competitive balance" in the sense that best incoming talent in each season is allocated to the worse teams to equalize NHL participating teams in the long term.

${ }^{22}$ For more details on the exact way how this system works, please visit: http://thehockeywriters.com/fixing-the-nhl-entry-draft-lottery-system-playoff-for-number-one/ 


\section{References}

Balafoutas, L., Lindner, F., and Sutter, M. (2012). Sabotage in tournaments: evidence from a natural experiment. Kyklos, 65(4):425-441.

Balsdon, E., Fong, L., and Thayer, M. A. (2007). Corruption in college basketball? evidence of tanking in postseason conference tournaments. Journal of Sports Economics, $8(1): 19-38$.

Berri, D. J. (2008). A simple measure of worker productivity in the national basketball association. The Business of Sport, 3:1-40.

Bognanno, M. L. (1990). An empirical test of tournament theory. Cornell University.

Borland, J., Chicu, M., and Macdonald, R. D. (2009). Do teams always lose to win? performance incentives and the player draft in the australian football league. Journal of Sports Economics, 10(5):451-484.

Dechenaux, E., Kovenock, D., and Sheremeta, R. M. (2015). A survey of experimental research on contests, all-pay auctions and tournaments. Experimental Economics, 18(4):609-669.

Dietl, H. M., Lang, M., and Werner, S. (2009). Social welfare in sports leagues with profitmaximizing and/or win-maximizing clubs. Southern Economic Journal, 76(2):375-396.

Dietl, H. M., Lang, M., and Werner, S. (2010). Corruption in professional sumo: An update on the study of duggan and levitt. Journal of Sports Economics, 11(4):383-396.

Duggan, M. and Levitt, S. D. (2002). Winning isn't everything: Corruption in sumo wrestling. American Economic Review, (92):1594-1607.

Ehrenberg, R. G. and Bognanno, M. L. (1990a). Do tournaments have incentive effects? Journal of Political Economy, 98(6):1307-1324.

Ehrenberg, R. G. and Bognanno, M. L. (1990b). The incentive effects of tournaments revisited: Evidence from the european pga tour. Industrial \& Labor Relations Review, $43(3): 74 \mathrm{~S}-88 \mathrm{~S}$. 
Fernie, S. and Metcalf, D. (1996). It's not what you pay. Centre for Economic Performance, London School of Economics and Political Science.

Fernie, S. and Metcalf, D. (1999). Its not what you pay its the way that you pay it and thats what gets results: Jockeys pay and performance. Labour, 13(2):385-411.

Florke, C. R. and Ecker, M. D. (2003). Nba draft lottery probabilities. American Journal of Undergraduate Research, 2(3):19-29.

Frick, B. (2003). Contest theory and sport. Oxford Review of Economic Policy, 19(4):512529.

Garicano, L. and Palacios-Huerta, I. (2005). Sabotage in tournaments: Making the beautiful game a bit less beautiful. CEPR Discussion Paper.

Gold, A. M. (2010). Nhl draft order based on mathematical elimination. Journal of Quantitative Analysis in Sports, 6(1).

Gold, A. M. (2011). Never too late to win. Journal of Quantitative Analysis in Sports, $7(2)$

Grier, K. B. and Tollison, R. D. (1994). The rookie draft and competitive balance: The case of professional football. Journal of Economic Behavior $\&$ Organization, 25(2):293298.

Lazear, E. P. and Rosen, S. (1981). Rank-order tournaments as optimum labor contracts. Journal of Political Economy, 89(5):841-864.

Lynch, J. and Zax, J. (1998). Prizes, selection, and performance in arabian horse racing (working paper 98-26). Boulder: University of Colorado, Departments of Economics.

Maxcy, J. G. (2002). Rethinking restrictions on player mobility in major league baseball. Contemporary Economic Policy, 20(2):145-159.

McIndoe, S. (2016). The guardian: Does the nhl have a tanking problem?

Parsons, C. A., Sulaeman, J., Yates, M. C., and Hamermesh, D. S. (2007). Strike three: Umpires' demand for discrimination. Technical report, National Bureau of Economic Research. 
Penrice, S. G. (1995). Applying elementary probability theory to the nba draft lottery. SIAM review, 37(4):598-602.

Preston, I. and Szymanski, S. (2003). Cheating in contests. Oxford review of Economic Policy, 19(4):612-624.

Price, J., Remer, M., and Stone, D. F. (2009). Sub-perfect game: Profitable biases of nba referees. Journal of Economics and Management Strategy, 21(1):2012.

Price, J., Soebbing, B. P., Berri, D., and Humphreys, B. R. (2010). Tournament incentives, league policy, and nba team performance revisited. Journal of Sports Economics, 11(2):117-135.

Price, J., Wolfers, J., et al. (2007). Racial discrimination among NBA referees. Centre for Economic Policy Research.

Quinn, K. G. (2008). Player drafts in the major north american sports leagues. The Business of Sport, 3:191-218.

Ralph, C. (2016). The hockey writers: Fixing the nhl entry draft lottery system - playoff for number on.

Rottenberg, S. (1956). The baseball players' labor market. The Journal of Political Economy, pages 242-258.

Sutter, M. and Kocher, M. G. (2004). Favoritism of agents-the case of referees' home bias. Journal of Economic Psychology, 25(4):461-469.

Szymanski, S. (2003). The economic design of sporting contests. Journal of Economic Literature, 41(4):1137-1187.

Szymanski, S. (2007). The champions league and the coase theorem. Scottish Journal of Political Economy, 54(3):355-373.

Taylor, B. A. and Trogdon, J. G. (2002). Losing to win: Tournament incentives in the national basketball association. Journal of Labor Economics, 20(1):23-41.

Tingling, P., Masri, K., and Martell, M. (2011). Does order matter? an empirical analysis of nhl draft decisions. Sport, Business and Management: An International Journal, $1(2): 155-171$. 
Zitzewitz, E. (2006). Nationalism in winter sports judging and its lessons for organizational decision making. Journal of Economics \& Management Strategy, 15(1):67-99.

\section{Appendix}

\subsection{Major Changes between 1988 and 2016}

How to qualify for the PO: The total number of 16 teams qualified for the PO remained the same over all years.

- 1988-1993: The total number of qualifiers consisted of the top four teams from each division during the season with two conferences and two divisions.

- 1994-1998: The PO structure became conference- rather then division-based with the same league structure as in the seasons before: Eight teams in each conference qualified for the PO; the teams with the best record in the divisions and the next best six teams in each conference also qualified for the PO.

- 1999-2013: The league reorganized its qualification requirements caused by the expansion of the league to three divisions (still two conferences). Now, the firstplaced teams in each division qualified. Of the remaining teams in each conference, the top five teams qualified for the remaining ten positions.

- 2013-2016: The league structure changed again and with it the rules for PO qualification. With the new four-division, two-conference system, the top three teams in each division qualified, with two wild cards in each conference. The wild cards went to the two teams in each conference that did not qualify directly (so it was possible that only three teams from one division qualified).

\begin{tabular}{llcccc} 
Seasons & \multicolumn{2}{c}{ Description } & \multicolumn{3}{c}{ Points } \\
& OT & $S O$ & $W$ & $T$ & $L$ \\
$1988-1999$ & Yes & No & 2 & 1 & 0 \\
$2000-2004$ & Yes & No & 2 & 1 & $0(\mathrm{Reg}) ; 1(\mathrm{OT})$ \\
$2006-2016$ & Yes & Yes & 2 & n/a & $0(\mathrm{Reg}) ; 1(\mathrm{SO}$ or OT $)$
\end{tabular}

Table 6: Point System (1988-2016) 


\section{National Hockey League 1988-1993}

\begin{tabular}{llllll}
\multicolumn{2}{c}{ Prince of Wales Conference } & \multicolumn{3}{c}{ Clarence Campbell Confere } \\
Adams & $1988-1992:$ & 5 Teams & Norris & $1988-1991:$ & 5 Teams \\
& $1993:$ & 6 Teams & & $1993:$ & 6 Teams \\
Patrick & $1988-1993:$ & 6 Teams & Smythe & 1988-1991: & 5 Teams \\
& & & & $1992-1993:$ & 6 Teams
\end{tabular}

Table 7: NHL structure 1988-1993

\section{National Hockey League 1994-2013}

\begin{tabular}{|c|c|c|c|c|c|}
\hline \multicolumn{3}{|c|}{ Eastern Conference } & \multicolumn{3}{|c|}{ Western Conference } \\
\hline Atlantic & $\begin{array}{l}\text { 1994-1998: } \\
\text { 1999-2013: }\end{array}$ & $\begin{array}{l}7 \text { Teams } \\
5 \text { Teams }\end{array}$ & Central & $\begin{array}{l}\text { 1994-1998: } \\
\text { 1999-2000: } \\
\text { 2001-2013: }\end{array}$ & $\begin{array}{l}6 \text { Teams } \\
4 \text { Teams } \\
5 \text { Teams }\end{array}$ \\
\hline Northeast & $\begin{array}{l}\text { 1994-1995: } \\
\text { 1996-1998: } \\
\text { 1999-2013: }\end{array}$ & $\begin{array}{l}7 \text { Teams } \\
6 \text { Teams } \\
5 \text { Teams }\end{array}$ & Pacific & $\begin{array}{l}\text { 1994-1995: } \\
\text { 1996-1998: } \\
\text { 1999-2013: }\end{array}$ & $\begin{array}{l}6 \text { Teams } \\
7 \text { Teams } \\
5 \text { Teams }\end{array}$ \\
\hline Southeast & $\begin{array}{l}\text { 1999: } \\
\text { 2000-2013: }\end{array}$ & $\begin{array}{l}4 \text { Teams } \\
5 \text { Teams }\end{array}$ & Northwest & $\begin{array}{l}\text { 1999: } \\
\text { 2000: } \\
\text { 2001-2013: }\end{array}$ & $\begin{array}{l}5 \text { Teams } \\
4 \text { Teams } \\
5 \text { Teams }\end{array}$ \\
\hline
\end{tabular}

Table 8: NHL structure 1994-2013

III. National Hockey League 2014-2016

\begin{tabular}{llllll}
\multicolumn{2}{l}{ Eastern Conference } & & \multicolumn{2}{l}{ Western Conference } \\
Atlantic & $2014-2016:$ & 8 Teams & Central 2014-2016: & 7 Teams \\
Metropolitan & $2014-2016:$ & 8 Teams & Pacific & 2014-2016: & 7 Teams
\end{tabular}

Table 9: NHL structure 2014-2016 


\begin{tabular}{|c|c|c|c|}
\hline$\underline{\text { Seasons }}$ & Teams & Seasons & Teams \\
\hline$\overline{1988-1991}$ & 21 & 1992 & 22 \\
\hline 1993 & 24 & 1994-1998 & 26 \\
\hline 1999 & 27 & 2000 & 28 \\
\hline 2001-2016 & 30 & & \\
\hline
\end{tabular}

Table 10: Total number of teams per season

\begin{tabular}{|c|c|c|c|}
\hline Seasons & Games & Seasons & Games \\
\hline 1988-1992 & 80 & 1996-2012 & 82 \\
\hline 1993-1994 & 84 & 2013 & 48 \\
\hline 1995 & 48 & 2014-2016 & 82 \\
\hline
\end{tabular}

Table 11: Games played (1988-2016)

$\begin{array}{lccc}\text { Structure } & \text { Season } & \text { Conference } & \text { Division } \\ \text { S1 } & 1988-1993 & - & 4 \\ \text { S2 } & 1994-1998 & 2 & - \\ \text { S3 } & 1999-2013 & 2 & 6 \\ \text { S4 } & 2014-2016 & 2 & 4\end{array}$

Table 12: League structure (1988-2016) 


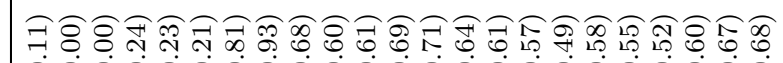

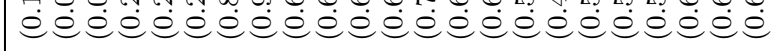

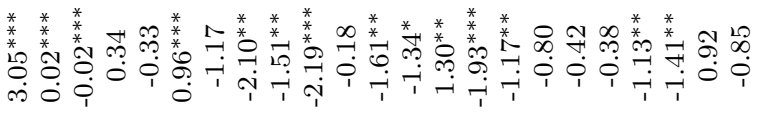

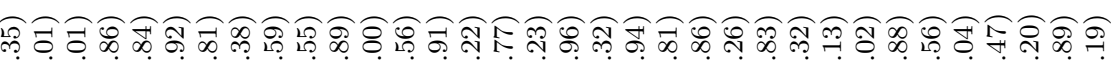

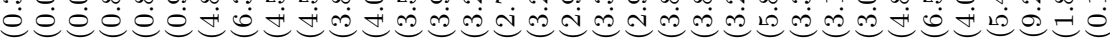

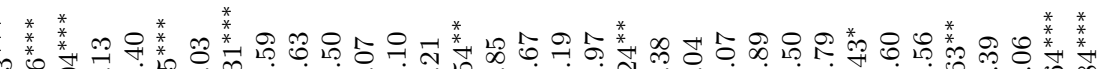
ه্

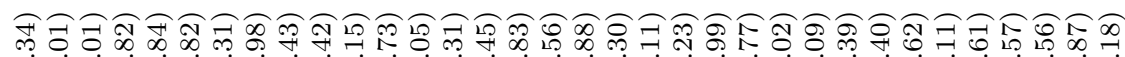
ele e e e d 1

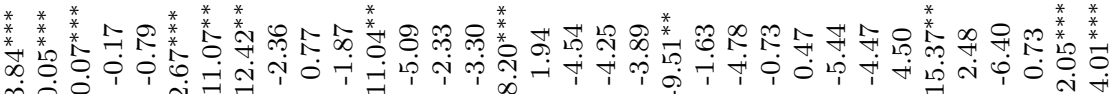
m $\mathrm{N} 7 \mathrm{~T}$

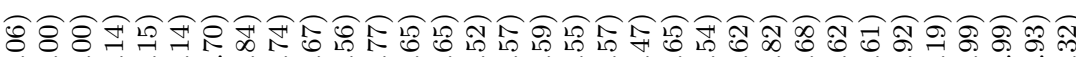

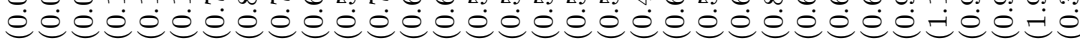

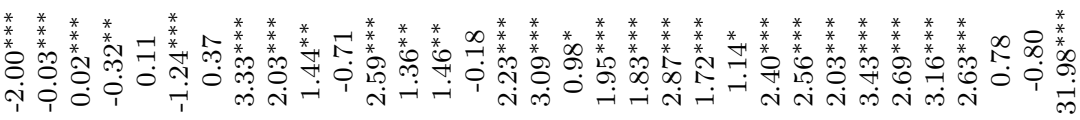

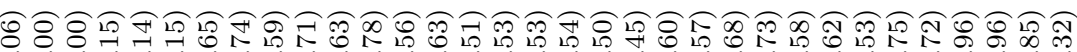

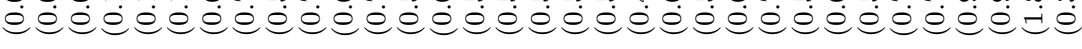

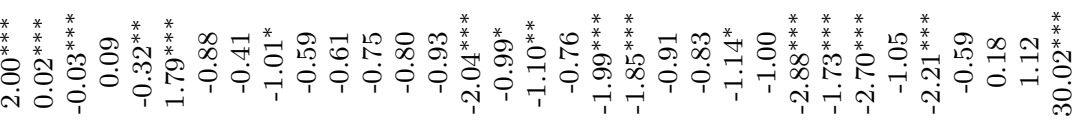

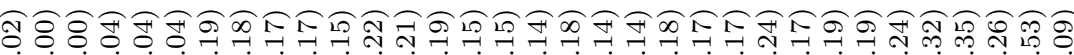

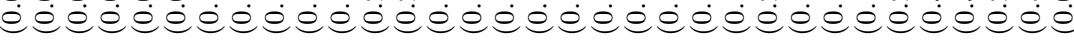

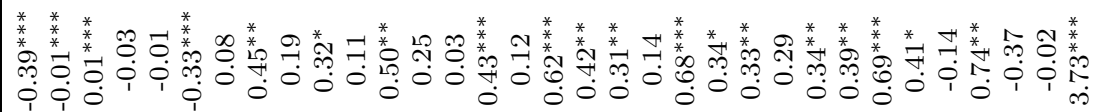

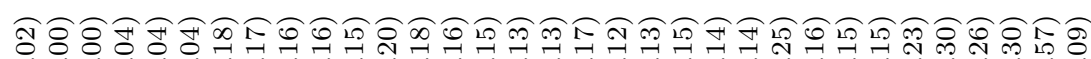

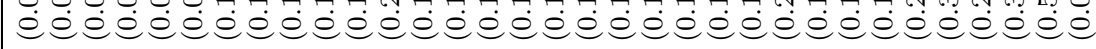

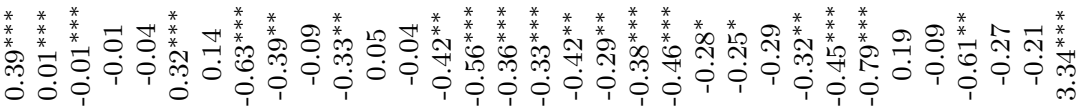

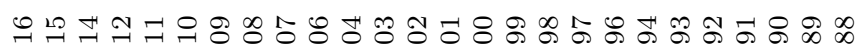

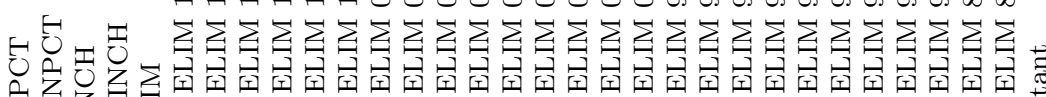

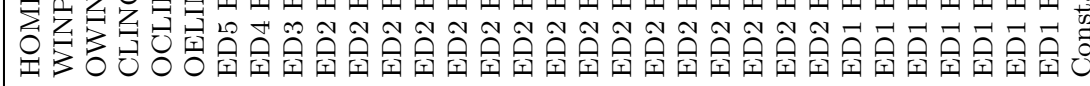

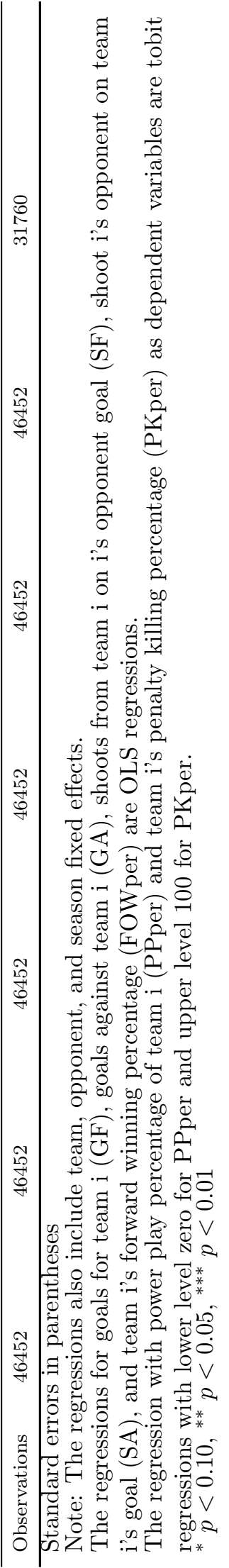


University of Innsbruck - Working Papers in Economics and Statistics Recent Papers can be accessed on the following webpage:

http://eeecon.uibk.ac.at/wopec/

2017-07 Helena Fornwagner: Incentives to lose revisited: The NHL and its tournament incentives

2017-06 Loukas Balafoutas, Simon Czermak, Marc Eulerich, Helena Fornwagner: Incentives for dishonesty: An experimental study with internal auditors

2017-05 Nikolaus Umlauf, Nadja Klein, Achim Zeileis: BAMLSS: Bayesian additive models for location, scale and shape (and beyond)

2017-04 Martin Halla, Susanne Pech, Martina Zweimüller: The effect of statutory sick-pay on workers' labor supply and subsequent health

2017-03 Franz Buscha, Daniel Müller, Lionel Page: Can a common currency foster a shared social identity across different nations? The case of the Euro.

2017-02 Daniel Müller: The anatomy of distributional preferences with group identity

2017-01 Wolfgang Frimmel, Martin Halla, Jörg Paetzold: The intergenerational causal effect of tax evasion: Evidence from the commuter tax allowance in Austria

2016-33 Alexander Razen, Stefan Lang, Judith Santer: Estimation of spatially correlated random scaling factors based on Markov random field priors

2016-32 Meike Köhler, Nikolaus Umlauf, Andreas Beyerlein, Christiane Winkler, Anette-Gabriele Ziegler, Sonja Greven: Flexible Bayesian additive joint models with an application to type 1 diabetes research

2016-31 Markus Dabernig, Georg J. Mayr, Jakob W. Messner, Achim Zeileis: Simultaneous ensemble post-processing for multiple lead times with standardized anomalies

2016-30 Alexander Razen, Stefan Lang: Random scaling factors in Bayesian distributional regression models with an application to real estate data

2016-29 Glenn Dutcher, Daniela Glätzle-Rützler, Dmitry Ryvkin: Don't hate the player, hate the game: Uncovering the foundations of cheating in contests

2016-28 Manuel Gebetsberger, Jakob W. Messner, Georg J. Mayr, Achim Zeileis: Tricks for improving non-homogeneous regression for probabilistic precipitation forecasts: Perfect predictions, heavy tails, and link functions 
2016-27 Michael Razen, Matthias Stefan: Greed: Taking a deadly sin to the lab

2016-26 Florian Wickelmaier, Achim Zeileis: Using recursive partitioning to account for parameter heterogeneity in multinomial processing tree models

2016-25 Michel Philipp, Carolin Strobl, Jimmy de la Torre, Achim Zeileis: On the estimation of standard errors in cognitive diagnosis models

2016-24 Florian Lindner, Julia Rose: No need for more time: Intertemporal allocation decisions under time pressure

2016-23 Christoph Eder, Martin Halla: The long-lasting shadow of the allied occupation of Austria on its spatial equilibrium

2016-22 Christoph Eder: Missing men: World War II casualties and structural change

2016-21 Reto Stauffer, Jakob Messner, Georg J. Mayr, Nikolaus Umlauf, Achim Zeileis: Ensemble post-processing of daily precipitation sums over complex terrain using censored high-resolution standardized anomalies published in Monthly Weather Review

2016-20 Christina Bannier, Eberhard Feess, Natalie Packham, Markus Walzl: Incentive schemes, private information and the double-edged role of competition for agents

2016-19 Martin Geiger, Richard Hule: Correlation and coordination risk

2016-18 Yola Engler, Rudolf Kerschbamer, Lionel Page: Why did he do that? Using counterfactuals to study the effect of intentions in extensive form games

2016-17 Yola Engler, Rudolf Kerschbamer, Lionel Page: Guilt-averse or reciprocal? Looking at behavioural motivations in the trust game

2016-16 Esther Blanco, Tobias Haller, James M. Walker: Provision of public goods: Unconditional and conditional donations from outsiders

2016-15 Achim Zeileis, Christoph Leitner, Kurt Hornik: Predictive bookmaker consensus model for the UEFA Euro 2016

2016-14 Martin Halla, Harald Mayr, Gerald J. Pruckner, Pilar García-Gómez: Cutting fertility? The effect of Cesarean deliveries on subsequent fertility and maternal labor supply

2016-13 Wolfgang Frimmel, Martin Halla, Rudolf Winter-Ebmer: How does parental divorce affect children's long-term outcomes?

2016-12 Michael Kirchler, Stefan Palan: Immaterial and monetary gifts in economic transactions. Evidence from the field 
2016-11 Michel Philipp, Achim Zeileis, Carolin Strobl: A toolkit for stability assessment of tree-based learners

2016-10 Loukas Balafoutas, Brent J. Davis, Matthias Sutter: Affirmative action or just discrimination? A study on the endogenous emergence of quotas published in Journal of Economic Behavior and Organization

2016-09 Loukas Balafoutas, Helena Fornwagner: The limits of guilt

2016-08 Markus Dabernig, Georg J. Mayr, Jakob W. Messner, Achim Zeileis: Spatial ensemble post-processing with standardized anomalies

2016-07 Reto Stauffer, Jakob W. Messner, Georg J. Mayr, Nikolaus Umlauf, Achim Zeileis: Spatio-temporal precipitation climatology over complex terrain using a censored additive regression model

2016-06 Michael Razen, Jürgen Huber, Michael Kirchler: Cash inflow and trading horizon in asset markets

2016-05 Ting Wang, Carolin Strobl, Achim Zeileis, Edgar C. Merkle: Scorebased tests of differential item functioning in the two-parameter model

2016-04 Jakob W. Messner, Georg J. Mayr, Achim Zeileis: Non-homogeneous boosting for predictor selection in ensemble post-processing

2016-03 Dietmar Fehr, Matthias Sutter: Gossip and the efficiency of interactions

2016-02 Michael Kirchler, Florian Lindner, Utz Weitzel: Rankings and risktaking in the finance industry

2016-01 Sibylle Puntscher, Janette Walde, Gottfried Tappeiner: Do methodical traps lead to wrong development strategies for welfare? A multilevel approach considering heterogeneity across industrialized and developing countries 


\title{
University of Innsbruck
}

\section{Working Papers in Economics and Statistics}

2017-07

Helena Fornwagner

Incentives to lose revisited: The NHL and its tournament incentives

\begin{abstract}
This paper analyzes data from a tournament, namely the National Hockey League regular scheduled season of games, which provides incentives to increase effort in order to reach the playoffs and incentives to decrease effort once a team has been eliminated from playoff considerations because of the entry draft. Our results show that teams indeed react to these dual incentives - they win more games when there is still a chance to reach the playoffs and lose more after being eliminated from playoff considerations. One can argue that losing more games after having no more chance to reach the playoffs could be the result of lower motivation or disappointment. This is the first study to show that this is not the only explanation for a higher amount of lost games. Instead, we find that there is a concrete strategy behind losing.
\end{abstract}

ISSN 1993-4378 (Print)

ISSN 1993-6885 (Online) 